\title{
POSSIBILISMO: VIDA E OBRA DE ALBERT O. HIRSCHMAN*
}

\author{
PHILIPP H. LEPENIES \\ TRADUÇÃO: OTACÍLIO NUNES JR.
}

\section{RESUMO}

Este artigo pretende desenredar as complicações da obra de Hirschman e revelar seu modo específico de investigação, tornando visíveis as influências biográficas multifacetadas sobre os textos acadêmicos de Hirschman. Expor a influência que momentos decisivos de sua vida tiveram sobre sua obra permite não só identificar e definir seu método de "possibilismo", mas também mostrar que essa abordagem continua a ser uma ferramenta multidisciplinar válida e útil para a análise social contemporânea não-ortodoxa.

PALAVRAS-CHAVE: Albert Hirschman; economia; análise social; possibilismo

\section{ABSTRACT}

This article intends to disentangle the intricacies of his work and to reveal his specific mode of investigation by making the multifaceted biographical influences on Hirschman's scholarly writings visible. Exhibiting the influence that decisive moments in his life had on his work not only allows us to identify and define his method of 'possibilism': it also shows that this approach remains a valid and useful multidisciplinary tool for unorthodox contemporary social analysis.

KEYWORDS: Albert Hirschman; economy; social analysis; possibilism.

[*] Texto publicado originalmente em Development and Change, vol. 39, $\mathrm{n}^{\mathrm{O}} 3,2008$, pp. 437-459 (C) Institute of Social Studies 2008). O autor agradece a Jeremy Adelman e aos pareceristas anônimos deste periódico pelos úteis comentários a uma versão anterior.

[1] Hirschman, Albert O.A propensity to self-subversion. Cambridge, MA: Harvard University Press, 1995, p. 111 .

[2] "A história subseqüente de minha vida e meu pensamento poderia provavelmente ser escrita em termos da progressiva descoberta de minha parte de quão certo meu pai estava" (Ibidem, p.122).
Numa noite de 1928, um estudante de ensino médio de Berlim conversa com o pai sobre a vida, o universo e tudo mais. A certa altura o pai, um renomado cirurgião da Charité, o hospital mais famoso de Berlim, confessa que não tem todas as respostas para as perguntas existenciais do filho. Um tanto chocado e desconcertado, o jovem sai correndo. Atravessa o longo corredor do apartamento burguês fin-de-siècle em que eles moram até o quarto de sua irmã mais velha, Ursula, e declara, pasmado: "Weißt Du was? Vati hat keine Weltanschauung" - "Sabe de uma coisa? O papai não tem Weltanschauung!", ou seja, nenhuma visão de mundo abrangente com base ideológica. O jovem é Albert Hirschman - e ele próprio admite que esse foi um dos acontecimentos mais decisivos de sua vida ${ }^{1}$. Naquela idade, jovem ainda, não ter uma Weltanschauung bem definida parecia a ele uma imperdoável deficiência de caráter. Em última instância, porém, não aderir cegamente a uma ideologia fixa tornou-se a marca registrada de sua obra científica, se não de sua vida inteira ${ }^{2}$. 
Aos primeiros raios de luz de uma manhã fria de céu claro em dezembro de 1940, um homem de 25 anos cruza secretamente a fronteira entre França e Espanha. Trilhas escondidas guiam seu caminho pelos Pireneus. Durante os últimos meses, ele colaborou com Varian Fry e o Comitê de Resgate de Emergência em Marselha, para ajudar a deixarem a França destacados emigrados europeus perseguidos pelos ocupantes alemães. Agora, os alemães estão num frenesi para capturálo. Seu apelido é "Sorridente". De acordo com sua Carte d'Identité francesa, seu nome é Albert Hermant. O verdadeiro nome do transgressor é Albert Hirschman.

Em 1995, um renomado economista escreve ironicamente que sua obra científica se caracteriza por "uma propensão à auto-subversão". Ao longo de sua carreira acadêmica, ele não só examina de forma crítica as teorias de colegas cientistas, mas também testa suas próprias teorias e até as altera completamente quando sente que perderam o valor explicativo. Parafraseando o famoso dito de Camus, ele declara que gosta de se ver como um Sísifo feliz, que lança abaixo de moto próprio a pedra de sua teoria e da teoria de outros acadêmicos, mas que ao mesmo tempo também extrai satisfação de tentar rolá-la acima de novo3. Esse Sísifo feliz também é Albert Hirschman.

Sem dúvida, a biografia de Hirschmané tão multifacetada quanto a obra acadêmica que o tornou um dos cientistas sociais mais originais do século XX. Contudo, dado que não fundou uma escola de pensamento específica nem desenvolveu uma teoria concisa que condensasse a essência de seus escritos, ele é normalmente associado a elementos específicos, aparentemente separados, de sua obra. Cientistas políticos o vinculam à saída e voz (1970); economistas do desenvolvimento, à abordagem do encadeamento (1958/1988); e historiadores, a paixões e interesses (1977) ou à retórica da reação (1991), para dar apenas alguns exemplos ${ }^{4}$. Essa redução a contribuições específicas, todavia, não capta o núcleo fundamental de sua obra e corre o risco de fazer com que Hirschman seja percebido unicamente como um combatente de batalhas históricas passadas. Por conseguinte, a relevância contemporânea e duradoura de sua obra é com freqüência despercebida.

Por exemplo, no debate ideológico atual, travado de forma feroz, sobre se a pobreza global deve ser reduzida por meio de mais um "grande impulso" na assistência ao desenvolvimento, como é exigido por Jeffrey Sachs5, ou antes por uma estratégia de "um passo de cada vez", como é advogado por William Easterly ${ }^{6}$, as idéias de Hirschman sobre desenvolvimento, que na verdade tocam em muitas das questões da presente controvérsia, não são evocadas por nenhuma das partes. $\mathrm{Da}$ mesma forma, Rodrik7 saúda uma recente publicação do Banco Mundial por inovar ao advertir pesquisadores e praticantes do desenvolvimento "a serem céticos em relação a soluções universais, abrangentes,
[3] Ibidem, p.92

[4] "O conceito de encadeamento alcançou o máximo sucesso: ele agora é uma parte tão integrada da linguagem da economia do desenvolvimento que o mais comum é seu criador não ser mencionado quando ele é invocado" (Idem, The strategy of economic development. Boulder, CO: Westview Encore, 1988, p. 223 - nova edição com um novo pós-escrito do autor).

[5] Sachs, Jeffrey D. The end of poverty: economic possibilities for our time. Londres: Penguin, 2005.

[6] William Easterly faz um apelo em favor de abordagens do tipo "um passo por vez" e critica Sachs por argumentar que a pobreza ou o subdesenvolvimento são apenas "um problema técnico que 'os principais praticantes do mundo' podem resolver" se receberem dinheiro suficiente (Easterly, William. "Carta ao Editor". New York Review of Books. 11 de Janeiro, 2007, p. 66).

[7] Rodrik, Dani. “Goodbye Washington Consensus, hello Washington Confusion". Journal of Economic Literature, vol. $44, \mathrm{n}^{\mathrm{O}} 4,2006$, p. 986. 
[8] A propósito, Rodrik recebeu o Albert O. Hirschman Prize de 2007.

[9] Easterly. The white man's burden: why the West's efforts to aid the rest have done so much ill and so little good. Nova York: Penguin, 2006; "Planners versus searchers in foreign aid". $\mathrm{ADB}$ Distinguished Speakers Programme, Manila:Asian Development Bank, 18 de jan. 2006.

[10] Ver, por exemplo, Chambers, Robert. Whose reality counts? Putting the first last. Harlow: Longman, 1996; Escobar,Arturo.Encountering development: the making and unmaking of the Third World. Princeton, NJ: Princeton University Press, 1995; Sachs, Wolfgang (ed.).The development dictionary: a guide to knowledge as power. Londres: Zed Books, 1991.

[11] Ellerman, David. Helping people help themselves: from the world bank to an alternative philosophy of development assistance. Ann Arbor, MI: University of Michigan Press, 2005.

[12] Ver, por exemplo, Ellerman, op. cit.; Foxley, Alejandro e outros (eds.). Development, democracy, and the art of trespassing: essays in honor of Albert $O$. Hirschman. Notre Dame, IN: Notre Dame Press, 1986; McPherson, Michael S. "Hirschman, Albert Otto". In: Eatwell, John, Milgate, Murray e Newman, Peter (eds.). The new palgrave economic development, Nova York: Norton, 1989; Meldolesi, Luca. Discovering the possible: the surprising world of Albert O. Hirschman. Notre Dame, IN: Notre Dame Press, 1995; Rodwin, Lloyd e Schön, Donald A. (eds.). Rethinking the development experience: essays provoked by the work of Albert O. Hirschman. Washington, DC: Brookings Institution, 1994; Teitel, Simon (ed.). Towards a new development strategy for Latin America: pathways from Hirschman's thought. Washington, DC: Inter-American Development Bank, 1992. de cima para baixo - não importando quão bem-intencionadas elas possam ser" - epordestacarque "a análiseeconômica, por mais difícil que seja, na falta de modelos específicos, tem de ser feita caso a caso"8. Os mesmos argumentos são expressos também por Easterly $9 \mathrm{em} \mathrm{seu}$ apelo para que, em vez de serem "planejadores" que agem de acordo com abordagens modelares, os praticantes do desenvolvimento devem antes ser "pesquisadores" e procurar o que é factível em qualquer conjunto dado de circunstâncias individuais. De fato, esse foi um dos principais apelos de Hirschman durante mais de cinqüenta anos. Mas não há nenhuma referência a ele nessas publicações. $O$ mesmo vale para a vasta literatura da abordagem pós-modernista que muitas vezes reflete a crítica de Hirschman em teorias grandiosas e abordagens tamanho-único sem, no entanto, mencioná-lo ${ }^{10}$. Uma exceção notável é Ellerman ${ }^{11}$, que faz uso explícito de Hirschman em seu desenho de uma filosofia do desenvolvimento alternativa.

Reconsiderar os textos de Hirschman parece, portanto, oportuno. Todavia, essa reconsideração não deve se limitar a suas idéias sobre desenvolvimento econômico. Naverdade, a principal originalidade de Hirschman reside em sua abordagem geral da solução de problemas e em seu método de análise. Esse modo específico de investigação caracteriza sua obra e congrega-lhe as partes individuais; acima de tudo, ele ainda pode ser usado de forma eficaz em muitas formas de análise social, não só no desenvolvimento. Contudo, condensar essa abordagem específica a partir de seus muitos - e à primeira vista desligados - textos e identificar seus elementos principais não é tarefa fácil.

Isso é em parte o resultado da recusa deliberada de Hirschman a construir uma teoria única. Em Shifting involvements (1982), ele defende abertamente que aceitemos as complexidades da vida real em vez de buscarmos teorias ou paradigmas que abranjam tudo. Não obstante, ao tornar visíveis as influências biográficas sobre as contribuições acadêmicas de Hirschman, é possível desenredar a complexidade de seus textos, identificar as constantes fundamentais de sua obra e revelar seu método analítico. É isso que este ensaio pretende fazer. A identificação dos leitmotiven científicos de Hirschman por meio de uma justaposição direta com sua vida normalmente não fez parte da literatura sobre ele ${ }^{12}$. Felizmente, o próprio Hirschman, depois de ter evitado por muitos anos investigar o gênero autobiográfico, começou, na segunda metade da década de 1990, a publicar alguns artigos autobiográficos muito curtos. Estes constituem a base das informações biográficas aqui reunidas.

Em ciência, em nítido contraste com as artes, a biografia de um cientista ou acadêmico normalmente não é abordada quando se discute sua obra acadêmica. Por trás disso está o ideal de universalidade e objetividade da ciência, em especial nas ciências naturais, mas tam- 
bém na economia, essa "rocha de solidez positivista"13. A obra de Hirschman, no entanto, é tão complexa que é só por meio da referência à sua biografia que conseguimos identificar em seus textos as questões e os tópicos vinculantes. Mais do que em muitos outros casos, quando se discute Hirschman, obra e vida não podem ser separadas. Ele uma vez chamou seu método de análise das questões latino-americanas de "possibilismo". Eu argumentaria que o "possibilismo" é, de fato, não apenas característico dos textos de Hirschman sobre desenvolvimento ou sobre a América do Sul, mas também seu método científico geral subjacente. Uma definição dessa abordagem ampliada do possibilismo exige a identificação dos leitmotiven que moldaram tanto a vida como a obra de Albert Hirschman. São estes a auto-subversão, a transgressão e ausência de Weltanschaauung. O possibilismo resultou dessas três características.

O restante deste ensaio discute a biografia e a obra acadêmica de Hirschman em ordem cronológica, dividindo-se em três partes. A primeira focaliza importantes acontecimentos biográficos até o final da década de 1940; a segunda examina as principais obras acadêmicas de Hirschman; e a parte final sumariza a essência do possibilismo, indicando o que acadêmicos, pesquisadores e praticantes do desenvolvimentismo contemporâneos podem aprender da vida e da obra de Albert O. Hirschman.

Neste ponto é preciso fazer dois esclarecimentos importantes. Primeiro, a separação entre fatos biográficos e contribuições acadêmicas em duas partes diferentes do artigo é não apenas intencional, mas também necessária. As principais influências biográficas que depois moldaram a abordagem científica de Hirschman ocorreram antes de ele ingressar na carreira acadêmica. É como se ele vivesse duas vidas apartadas, uma como antifascista e refugiado, outra como economista de renome. Essas duas fases não se sobrepõem; são seqüenciais. Como este ensaio é escrito em ordem cronológica, os principais eventos da vida de Hirschman anterior à partida da Europa para os Estados Unidos são sumarizados antes de destacar suas obras acadêmicas. Nos textos posteriores, Hirschman usou conscientemente suas experiências quando jovem. É evidente que experiências pessoais posteriores a 1945 também tiveram um impacto importante sobre seu trabalho, mas para entender os temas recorrentes nas obras é preciso focalizar sua vida antes da chegada aos Estados Unidos. Em segundo lugar, Hirschman manifestou sua "propensão à auto-subversão" na reinterpretação que fez de três diferentes temas, a saber, o papel das assimetrias nas relações internacionais (originalmente da década de 1940), o conceito de crescimento desequilibrado (década de 1950) e saída evoz (década de 1970). Para tornarvisível o processo de auto-subversão, resumi todos os escritos de Hirschman sobre cada um desses tópicos no
[13] Hirschman. Essays in trespassing: economics to politics and beyond. Cambridge: Cambridge University Press, 1981, p. 294. 
[14] Idem, A propensity to self-subversion, op. cit., p.116.

[15] Keynes, John Maynard.The general theory of employment, interest, and money. Cambridge: Cambridge University Press, 1973 [1936]. momento em que discuto o texto original. Num sentido estrito, isso contradiz a organização cronológica do ensaio, mas é a única forma de evitar confusões posteriores.

\section{A LUTA CONTRA O FASCISMO - BERLIM, PARIS, LONDRES}

Albert Hirschman nasceu em Berlim, em 1915, e recebeu o nome Otto-Albert Hirschmann. Embora seus pais fossem judeus, elee a irmã foram batizados como protestantes. Como ocorria a muitos dos judeus prussianos assimilados da classe média alta, a religião e a prática religiosa não eram uma questão importante na família Hirschmann.

Hirschman estudou no Lycée Français de Berlim, uma escola de elite, e concluiu seu baccalauréat pouco antes de os nacional-socialistas assumirem o poder. Envolveu-se ativamente na organização de jovens do Partido Social-Democrata (SPD), no mesmo grupo do jovem Willy Brandt. Algumas semanas depois de o Reichstag ter sido consumido pelas chamas, seu pai morreu de câncer. A morte do pai, junto com o crescente anti-semitismo e as primeiras medidas legislativas antidemocráticas do governo de Hitler, persuadiu Hirschman a emigrar para a França. Em abril de 1933, ele partiu de Berlim para Paris. Já havia começado a estudar economia na Universidade de Berlim; em Paris, matriculou-se na École des Hautes Études Commerciales (HEC). Os cursos de geografia econômica feitos lá exerceriam sobre ele um impacto duradouro. A sensibilização pelo físico, o topográfico, bem como pelas peculiaridades sociais de países específicos entranhou nele uma tendência a olhar com ceticismo qualquer teoria que definisse os prerrequisitos do progresso unicamente em termos de indicadores macroeconômicos como investimento, poupança, razões capital/produto ou renda, sem levar em conta outros traços característicos do país em questão ${ }^{14}$. Depois de ter obtido seu primeiro diploma, em 1935, Hirschman ganhou uma bolsa de um ano na London School of Economics. Foi durante sua estada na Inglaterra que o economista John Maynard Keynes destroçou as fundações da economia com a publicação de sua Teoria geral ${ }^{15}$.

\section{RESISTÊNCIA ATIVA: ESPANHA, ITÁLIA E FRANÇA}

Aovoltarà França,em 1936, Hirschman decidiu participarda Guerra Civil Espanhola e viajou para Barcelona para se alistar nas Brigadas Internacionais. Combateu cerca de duas semanas, mas partiu quando sua unidade ia ser transferida para a defesa de Madri. Os atritos dentro da Brigada e a forte influência que os comunistas stalinistas começaram a exercer o desiludiram. Como ainda tinha um passaporte válido do Reich alemão, ele não teve dificuldade de deixar o país. 
De 1936 a 1938 Hirschman trabalhou em seu Ph.D. na Universidade de Trieste, na Itália. Seus primeiros textos acadêmicos foram publicados nessa época, principalmente sobre questões da economia italiana. Em comparação com as batalhas teóricas correntes que eram travadas na ciência econômica, sua abordagem era bastante heterodoxa.As explicações que ele propunha para fenômenos demográficos ou econômicos da sociedade italiana se baseavam mais em estatísticas do que em discussões teóricas. Para Hirschman, era "um grande alívio perceber que se podia fazer um trabalho toleravelmente competente em economia sem ter de resolver se Keynes [...] tinha todas as respostas corretas" 16 .

Hirschman escolheu Trieste porque ali tinha a possibilidade de ficar com a irmã Ursula, que havia se mudado para a cidade com o marido, o filósofo italiano Eugenio Colorni. Colorni pertencia a um grupo de antifascistas determinados e ativos do qual Hirschman logo se tornou membro. Ele ficou fascinado com o fato de os membros do grupo concordarem sobre a necessidade de combater o fascismo, mas não justificarem suas ações recorrendo a uma ideologia específica. De fato, Colorni e seu grupo cultivavam uma posição intelectual de ceticismo que não tomava nada como dado, a não ser suas próprias dúvidas. Que isso não resultasse em melancolia ou inatividade, ao contrário, provocasse ação e resistência, era uma percepção completamente nova para Hirschman, que ainda acreditava firmemente na necessidade de se ter uma Weltanschauung para guiar a ação. Os membros do grupo de Colorni, sem bases ideológicas universalmente acordadas, apenas não tinham disposição para tolerar as limitações das liberdades pessoais e a crescente injustiça do regime de Mussolini, e extraíam uma profunda satisfação da resistência ativa e do combate ao fascismo. A influência de Colorni sobre Hirschman foi muito importante: foi por meio de sua experiência em Trieste que ele pouco a pouco começou a questionar se era preciso realmente ter uma base ideológica firme na vida. Em 1928 , Colorni foi preso. Hirschman evitou sua própria detenção voltando às pressas para Paris. Em 1944, Colorni foi morto por fascistas italianos.

Depois que os alemães atacaram a França, em 1940, Hirschman alistou-se no exército francês. Combateu em uma unidade constituída principalmente de jovens alemães e italianos emigrados. Enquanto se retiravam para o Sul da França, os soldados convenceram seu oficial a lhes fornecer documentos militares com identidades falsas, para evitar a execução imediata se fossem apanhados pelos soldados alemães. Albert Hirschman se tornou Albert Hermant.

De julho a dezembro de 1940, ele se juntou a Varian Fry em Marselha. Financiados pelo Comitê de Resgate de Emergência americano, que havia sido formado a pedido de Erika Mann e outros intelectuais norte-americanos e europeus emigrados, Fry e seus ajudantes possi-
[16] Hirschman. A propensity to selfsubversion, op. cit., p.118. 
[17] Fry, Varian. Surrender on demand. Nova York: Random House, 1946; ver também a nova edição, com introdução de Albert O. Hirschman: Assignment: rescue - an autobiography. Nova York: Scholastic, 1993.
[18] Aintrodução que Hirschman escreveu para a nova edição do relato de Varian Fry (Assignment: rescue..., op. cit.) foi reimpressa em Hirschman, A propensity to self-subversion, op. cit. Outras informações foram dadas em Hirschman, Crossing boundaries: selected writings. Nova York: Zone Books, 1998. bilitaram que mais de 200 mil refugiados alemães e de outras nacionalidades deixassem a França e evitassem ser presos, entre eles intelectuais, artistas e políticos de Weimar proeminentes como Hannah Arendt, Max Ernst, Lion Feuchtwanger, Siegfried Kracauer, Heinrich e Golo Mann, bem como Franz Werfel. Não havia possibilidade legal deos emigrados em dificuldade deixarem a França, mas as autoridades espanholas normalmente concediam vistos para Portugal e travessia em barcos salva-vidas para o exterior. O desafio, portanto, era encontrar formas deentrar na Espanha sem ser apanhado pela polícia francesa ou alemã.A principal responsabilidade de Hirschman era organizar vistos legais e forjados para Estados Unidos, Brasile China eencontrar trilhas secretas para cruzar os Pireneus. Foi por uma dessas trilhas que o próprio Hirschman partiu para os Estados Unidos em 1940, sabendo que os alemães estavam à sua procura.

Hirschman poucas vezes comentou sobre seu trabalho com o comitê, normalmente apontando para o relato feito por Varian Fry: Surrender on demand ${ }^{17}$. Os casos trágicos daqueles que não puderam ser salvos pelo comitê e tiveram uma morte prematura - como Walter Benjamin ou os políticos Rudolf Breitscheid (um socialdemocrata proeminente na República de Weimar e ex-ministro do Interior da Prússia) e Rudolf Hilferding (ministro das Finanças em Weimar) - pareciam pesar tanto sobre Hirschman que ele não sentia nenhuma urgência de falar publicamente sobre seu papel na salvação da vida de muitos outros. Além disso, os feitos de Fry permaneceram amplamente não reconhecidos e não apreciados nos Estados Unidos durante muitos anos depois da Guerra. Foi só no começo da década de 1990, quando uma exposição no recéminaugurado Museu Memorial do Holocausto, em Washington DC provocou um ressurgimento do interesse nas façanhas de Fry, que Hirschman deu um testemunho - ainda que escasso - de seu próprio papelis.

\section{TRANSGRESSÃO VOLUNTÁRIA}

Em dezembro de 1940, uma bolsa da Rockefeller Foundation possibilitou que Hirschman assumisse um cargo de pesquisador em Berkeley. Lá ele dividia uma sala com outro economista-emigrado, Alexander Gerschenkron, que, como Hirschman, se tornaria um dos pais fundadores da economia do desenvolvimento. O primeirolivrode Hirschman, National power and the structure of foreign trade, foi publicado em 1945. Em contraste com a teoria do comércio neoclássica, que proclama que o comércio internacional é benéfico para todos os parceiros comerciais, Hirschman, usando o exemplo da Alemanha pré-guerra, mostrou que o simples peso econômico capacitou o império alemão a 
exercer uma influência política considerável sobre alguns países europeus orientais menores. A descrição desses efeitos políticos negativos do comércio e da dependência política resultante das desigualdades econômicas internacionais antecipou muitos argumentos empregados pela teoria da dependência da década de 1960, cujos proponentes prontamente reivindicaram Hirschman como um dos seus.

Hirschman, no entanto, opunha-se a essa instrumentalização. Com o tempo, ele sentiu o impulso auto-subversivo de esclarecer e emendar seus argumentos anteriores. No famoso ensaio "Beyond asymmetry" 19 , ele contra-argumentou que economias pequenas não estão automaticamente condenadas à eterna dependência. Ao contrário, a importância relativamente pequena que elas têm em relação ao vizinho potente e grande na verdade abre uma janela de mudança possível. Dado que o volume de comércio com o país pequeno é só uma fração do que o país grande comercia, as assimetrias econômicas se refletem em uma assimetria de atenção: o país grande dá muito mais atenção a outros países que têm tamanho similar ao seu do que a Estados pequenos. O país pequeno pode então tirar vantagem dessa assimetria de atenção introduzindo na economia mudanças estruturais como diversificação, substituição de importações e abertura de novos mercados.

Hirschman criticou abertamente a teoria da dependência e seus próprios textos anteriores por identificarem só o status quo negativo da dependência política e econômica, sem sugerir como mudar essa situação, exceto, talvez, pela defesa ingênua de soluções deus ex machina (tais como conclamar acordos internacionais para pôr fim aos problemas). Em contraste, a obra de Hirschman propaga a necessidade de identificar "modificadores ou remédios embutidos" e de explorar se o sistema pode conter as "sementes de sua própria destruição" que permitam reduzir a dependência a partir de dentro.

Em 1943, Hirschman integrou-se como voluntário ao exército e tornou-se cidadão norte-americano. O funcionário da imigração quis mudar-lhe o nome de Albert Hirschmann para Albert Hirshman. Ele se recusou e foi autorizado a manter o " $c$ " se sacrificasse um "n". Serviu no norte da África e na Itália, e voltou aos Estados Unidos em 1946.

\section{UMA ESTRATÉGIA NÃO-ORTODOXA DE DESENVOLVIMENTO}

De 1946 a 1952 Hirschman trabalhou no Federal Reserve Board em Washington, em questões do Plano Marshall para a reconstrução da Europa Ocidental. Durante esse período, desenvolveu um interesse pela teoria do desenvolvimento econômico. Assumiu um cargo de assessor econômico do governo da Colômbia e, em 1952,
[19] Hirschman, "Beyond asymmetry: critical notes on myself as a young man and on some other old friends". International Organization, vol. $32, \mathrm{n}^{\circ}$ 1,1978, pp. 45-50. 
mudou-se para Bogotá, onde mais tarde abriu sua própria empresa independente de consultoria. De tempo em tempos, viajava aos Estados Unidos para apresentar textos em conferências sobre suas experiências com o processo de desenvolvimento. Suas contribuições causaram tanto rebuliço na comunidade de economistas do desenvolvimento que ele foi convidado pela Universidade Yale para condensar suas observações em um livro. O resultado foi o memorável Strategy of economic development (1958). Depois da publicação desse livro, Hirschman recebeu a oferta de uma cátedra em Columbia, depois em Harvard e por fim no Institute for Advanced Study em Princeton (onde é agora professor emérito).

Strategy atacava diretamente a teoria da modernização prevalecente esuaidéiade "crescimentoequilibrado" (Paul Rosenstein-Rodan, Ragnar Nurkse), segundo a qual países subdesenvolvidos necessitavam de um "grande impulso" - uma série de investimentos simultâneos com o objetivo de estabelecer todas as indústrias relevantes ao mesmo tempo. Fortemente influenciados pelos aparentes sucessos das primeiras décadas de planejamento econômico na União Soviética, pelo keynesianismo, com sua ênfase no papel ativo que o governo deveria desempenhar na economia, pelo método de cálculo de insumo-produto de Leontief, que deu uma base matemática ao planejamento, bem como pelo instrumento recém-criado de elaboração de contas nacionais e de macrodados estatísticos como o Produto Nacional Bruto, os proponentes da teoria da modernização acreditavam que uma economia subdesenvolvida era comparável a um aparelho técnico que poderia sofrer um ajuste fino por meio de interferência externa e deveria seguir estritamente modelos padronizados do mundo desenvolvido.

Hirschman, ao contrário, afirmava que a maneira de avançar era fazer o oposto exato, isto é, concentrar-se no "crescimento desequilibrado". Enquanto o modelo de crescimento equilibrado acarreta um montante exagerado e pouco prático de planejamento detalhado, a abordagem de Hirschman era mais pragmática e mais fácil de implementar. Segundo ele, as decisões de investimento deviam ser tomadas de acordo com as prioridades e as possibilidades financeiras e tecnológicas disponíveis e deveriam tratar de uma coisa por vez. Por conseguinte, o desenvolvimento não deveria ser percebido como uma gigantesca matriz ex-ante de investimentos paralelos necessários, cobrindo uma miríade de setores; antes, o desenvolvimento deveria ser pensado como uma seqüência de investimentos. A abordagem é apelidada de "desequilibrada" porque os investimentos começam concentrando-se em um único setor. Dado que países pobres carecem de recursos para investir em todos os setores relevantes ao mesmo tempo, o crescimento equilibrado só pode ser uma meta de longo prazo que idealmente será o resultado do crescimento desequilibrado. E 
enquanto os modelos de desenvolvimento daquela época enfatizavam a necessidade de planejamento, Hirschman acreditava que o mercado cumpria um papel importante na moldagem e na orientação dos investimentos necessários por meio das preferências reveladas pela demanda do mercado. Esse foco nas forças do mercado, todavia, não deve ser entendido no sentido da euforia neoliberal com o livre-mercado. Por trás dele há um ceticismo em relação a uma demasiada interferência externa na política de desenvolvimento. Hirschman acreditava que os processos econômicos que se desenvolviam e se manifestavam no Terceiro Mundo deviam ser aqueles que guiariam as futuras políticas de desenvolvimento e os investimentos - não as abordagens modelares dos planejadores.

O conceito de "encadeamentos" explica como funciona o crescimento desequilibrado. Em relação à produção de um determinado bem, os investimentos podem ser feitos ou olhando para trás ou olhando para frente no processo de produção:

Primeiro, uma operação industrial existente, dependendo inicialmente de importações não só para suas máquinas e equipamentos, mas também para muitos de seus insumos materiais, faria pressões para a fabricação doméstica desses insumos e por fim para uma indústria doméstica de bens de capital. Essa dinâmica foi chamada de encadeamentos para trás, já que a direção do estímulo para investimento adicional flui do artigo acabado para os materiais brutos ou semiprocessados dos quais ele éfeito ou para as máquinas que ajudam a fazê-lo. Outro estímulo para investimento adicional aponta na outra direção ée, portanto, chamado de encadeamentos para frente: a existência de uma dada linha de produto $A$, que é um bem final oué usado como um insumo na linha $B$, age como um estimulante para o estabelecimento de outra linha $C$, que também pode usar $A$ como insumo ${ }^{20}$.

Segundo Hirschman, é naqueles setores que propiciam a maioria dos encadeamentos que devem ser feitos investimentos. Assim, as decisões de investimento não devem ser guiadas apenas pelo produto esperado, mas também pelo grau em que os investimentos iniciais levarão a investimentos adicionais.

Trinta anos depois da publicação de Strategy, Hirschman sentiu mais uma vez necessidade de subverter suas idéias originais. Baseado em lições aprendidas da implementação delas, ele admitiu que não havia reconhecido as conseqüências políticas do crescimento desequilibrado. Isso significava

[...] que esse crescimento poderia implicarpor algum tempo um declínio real nas rendas do setor que inicialmente não se expandia [...]. Quando a indús-
[20]Idem. "Linkages". In: Eatwell, John, Milgate, Murray e Newman, Peter (eds.), op. cit., pp. 210-211. 
[21] Idem. The strategy of economic development. Boulder, $\mathrm{CO}$ : Westview Encore,1988,pp.28 e32 (nova edição com um novo pós-escrito do autor).

[22] Ibidem, p.31.

[23] Como Kuznets, Simon. "Economic growth and income inequality". American Economic Review, vol. $45, \mathrm{n}^{\circ} 1,1955$. tria avança [em um setor] e usa os recursos de energia e transporte existentes, na ausência de excesso de capacidade, há menos desses recursos disponíveis para os usuários tradicionais, que, portanto, estarão em pior situaçãa ${ }^{21}$

Assim, no processo de crescimento seqüencial que ele propagava, os receptores de renda de um setor podiam de fato estar ganhando à custa daqueles de outros setores.

Em outras palavras, os investimentos em apenas um setor resultam no negligenciamento de outros setores, o que subseqüentemente chama a atenção pública. As crescentes críticas resultantes levam então a uma mudança de curso, a uma nova concentração de investimentos em outros setores - e outra vez a um novo negligenciamento. Para Hirschman, esse padrão de investimento em ziguezague, ao qual ele se refere com mais precisão como "crescimento antagônico" é, todavia, "adequado ao sistema democrático" e pode ser "o padrão característico, e mesmo o único disponível, de progresso em uma sociedade que vive segundo as regras da política competitiva. Uma tal sociedade é necessariamente dividida em "os de dentro" e "os de fora", com os interesses e as aspirações destes últimos sendo negligenciados até que seja a vez deles de assumir o controle e inverter a situação em relação a seus oponentes ${ }^{22}$. É interessante que esse padrão em ziguezague só é possível porque a desigualdade crescente é tolerada por algum tempo antes que se instale o protesto.

Enquanto alguns economistas ${ }^{23}$ proclamavam que a desigualdade surge no início do processo de desenvolvimento e deve idealmente se reduzir depois, Hirschman buscava as razões psicológicas que podiam explicar por que a desigualdade crescenteé tolerada - ao menos por algum tempo - por aqueles deixados de fora, como se mostrou no curso do crescimento antagônico.A resposta, ele argumentava, está na existência do que ele chama de "efeito túnel":

Suponha que eu dirija por um túnel com duas pistas, ambas indo na mesma direção, e entro em um sério congestionamento. Até onde consigo ver (que não é muito longe) nenhum carro se move em nenhuma das pistas. Estou na pista da esquerda e fico desanimado. Passado algum tempo os carros na pista da direita começam a se movimentar. Naturalmente, fico consideravelmente animado, pois sei que o congestionamento foi rompido e que a vez de minha pista se movimentar decerto ocorrerá a qualquer momento. Embora esteja parado, me sinto muito melhor do que antes por causa da expectativa de que logo me moverei.Mas suponha que a expectativa éfrustrada e só a pista da direita continue a se movimentar: nesse caso eu, junto com meus co-sofredores de pista, suspeitarei de desonestidade, e muitos de nós em algum momento ficaremos muito furiosos 
e dispostos a corrigir a injustiça por meio de ações diretas (como cruzar ilegalmente a linha dupla que separa as duas pistas $)^{24}$.

Usando esse exemplo simples, Hirschman explicava por que uma situação subótima (o fato de outros carros se movimentarem ou, em termos de desenvolvimento econômico, de as rendas de outros crescerem) é tolerado por algum tempo por aqueles deixados de fora. Esse intervalo entre a identificação de um problema e a ação contra ele em outras palavras, o intervalo de tempo de tolerância -, embora intuitivamente convincente, contradizia o modelo simples do homo oeconomicus racional, que se espera que reaja instantaneamente no momento em que suas preferências não são atendidas.

Contudo, mesmo esse padrão de crescimento antagônico que ziguezagueia entre dois setores não deixa de ter falhas, como confessou Hirschman em mais um texto auto-subversivo. Hirschman ficou estarrecido de saber que a junta militar argentina afirmava ter se inspirado em seu modelo de crescimento desequilibrado quando justificava a concentração de seus esforços no crescimento econômico antes de restaurar a democracia, argumentando que as metas econômicas, sociais e políticas não podiam ser atingidas de imediato. No argumento original de Hirschman, o desequilíbrio forçado causado pelo crescimento desequilibrado ou antagônico era autocorretivo devido à reação das forças de mercado e às respostas das políticas públicas. A interpretação argentina, no entanto, mostrava que a idéia de "uma coisa por vez" pode ter conseqüências desastrosas. No caso da Junta Militar, o progresso econômico bem-sucedido poderia tornar os governantes tão populares que a maioria não sentiria nenhuma necessidade de redemocratizar o país. Assim, nem todos os desequilíbrios põem em jogo forças equilibradoras, e a resolução seqüencial de problemas comporta o risco de estacar:

Procurarsoluções uniformes para problemas de desenvolvimento invariavelmente nos desencaminha; isso ocorre igualmente para os imperativos de simultaneidade e seqüencialidade, ou seja, para a insistência no "planejamento integrado" assim como para a injunção de adiar certas tarefas em nome de "uma coisa porvez"25.

Hirschman reconhecia assim os riscos do crescimento desequilibrado: todavia, ele deixava claro que identificar esses riscos não significa que não se deva agir, ou que a teoria do crescimento equilibrado deva ser reabilitada. Antes, ele aceitava que as questões em jogo são tão complexas quanto à realidade que nos cerca e que em qualquer caso é impossível definir um "melhor caminho único".
[24] Hirschman. "The changing tolerance for income inequality in the course of economic development". In: Essays in trespassing: economics to politics and beyond. Cambridge: Cambridge University Press, 1981, p. 41.

[25] Idem, A propensity to self-subversion, op. cit., p. 76 . 
[26] Idem, The strategy of economic development, op.cit., p.11.

[27] Ibidem, p. 26.

[28] Ibidem, p. 5 .

\section{ENTRA EM CENA O POSSIBILISMO}

Essa negação de um "melhor caminho único" está no cerne da teoria do desenvolvimento de Hirschman, que foi mais elaborada em seus escritos subseqüentes, a saber, Journeys towards progress (1963) e Abias for hope (1971). Ao passo que as primeiras teorias do desenvolvimento econômico identificavam gargalos financeiros ou tecnológicos como as principais razões para o subdesenvolvimento e conclamavam a remoção desses obstáculos por meio de prescrições de política uniformes, Hirschman questionava a utilidade e a aplicabilidade dessas abordagens universais baseadas em teorias que normalmente não levam em conta as peculiaridades locais. Em particular, ele pretendia combater a "síndrome do economista visitante", que ele define como "o hábito de emitir conselhos e prescrições peremptórios sugerindo a adoção de princípios e remédios universalmente válidos - sejam eles velhos ou novinhos em folha - depois de uma familiarização estritamente mínima com o "paciente" 26 . Um argumento que foi depois vocalizado proeminentemente por adeptos do discurso pós-moderno da década de 1990 sem referência a Hirschman.

Como alternativa, Hirschman propunha buscar "mecanismos de indução" ou "artifícios de regulação do ritmo" que promovessem a mudança a partir de dentro ${ }^{27}$ - um conceito semelhante aos modificadores ou remédios embutidos antes mencionados. Esses mecanismos são importantes na medida em que

[...] o desenvolvimento depende não tanto de encontrar combinações ótimas para recursos e fatores de produção dados como de pôr em ação e arregimentar para propósitos de desenvolvimento recursos e capacidades que estão ocultos, dispersos ou mal utilizados 28

Isso, no entanto, é mais fácil de falar do que de fazer, dado que os próprios países costumam não conseguir tirar proveito de seus potenciais de desenvolvimento endógenos, principalmente porque estes não são percebidos e identificados como tais. Uma das principais razões para isso é que a idéia de mudança pode de fato agir como um obstáculo à mudança, sobretudo se a mudança for percebida meramente como um processo de "alcançar" o mundo desenvolvido. Comoessaidéia de mudança se baseia nas experiências dos países desenvolvidos, não nas dos subdesenvolvidos, ela pode levar a concepções equivocadas e noções exageradas sobre como deveria ser a mudança e como deveria ser fomentada. De fato, essas concepções equivocadas e essa incapacidade de identificar as peculiaridades locais da mudança são um resultado da separação conceitual do mundo subdesenvolvido e desenvolvido, na qual o padrão de comparação é sempre estabelecido pelos países desenvolvidos. 
As experiências de Hirschman com as elites governantes da América Latina levaram-no a cunhar o termo fracasomanía. Ele descreve a tendência de novos governos a acreditar e proclamar que todos os esforços do governo anterior foram um completo fracasso (fracaso), sem conseguir filtrar as medidas que podem conduzir ao desenvolvimento e ao progresso. Isso resulta, então, na aplicação de um conjunto completamente novo de políticas gerais, muitas vezes a pedido dos "economistas visitantes" com quem as elites trabalham numa associação íntima, e que em última instância impedem os decisores locais de aprender com sua própria experiência.

Hirschman advoga uma fuga dos "constructos camisa-de-força" de políticas baseadas em generalizações, leis universais e seqüências fixas, buscando em vez disso a singularidade ou os aspectos singulares de uma determinada situação. Isso permitiria a identificação de possíveis "avenidas de escape". Ele chama essa abordagem de "possibilismo". Ela se baseia na crença de que a mudança em qualquer cenário é possível, mas que a identificação dos agentes da mudança requer uma propensão a buscar racionalidades ou interpretações dos cenários locais ocultas e que à primeira vista podem ser contra-intuitivas. Hirschman vê o possibilismo como:

[...] uma abordagem do mundo social que enfatizaria o único em vez do geral, o inesperado em vez do esperado, e o possível em vez do provável. Pois a inclinação fundamental de meus textos foi ampliar os limites do que épercebido como possivel, ainda que ao custo de rebaixar nossa capacidade, real ou imaginária, de discernir o provável29.

O possibilismo é, portanto, uma ferramenta de análise baseada antes em pressupostos cognitivos do que nos pressupostos do homo oeconomicus racional. A busca de racionalidades ocultas ou contra-intuitivas foi, é claro, característica dos textos de autores clássicos como Adam Smith e Mandeville. A importância da contribuição de Hirschman é que ele faz um apelo em favor de uma abordagem livre de ideologias e flexível da análise dos fenômenos socioeconômicos - um de seus ensaios, por exemplo, tem o título "A busca de paradigmas como um obstáculo ao entendimento" ${ }^{\circ}$. O possibilismo é, então, a antítese dafracasomanía.

Para aplicar a abordagem possibilista à análise de uma situação específica, podem ser usadas várias ferramentas ou artifícios conceituais. Um deles é a noção da "bênção (ou maldição) disfarçada", isto é, a idéia de que um aspecto identificado como negativo pode de fato carregar um efeito positivo até então não reconhecido que poderia ser mais fomentado.Assim, o "queé um obstáculo ao progresso em um cenário e em um estágio pode ser útil em circunstâncias diferentes"31. Outro
[29] Idem. A bias for hope: essays on development and Latin America. New Haven, CT: Yale University Press, 1971, p. 28.

[30] In: Ibidem.

[31] Idem, The strategy of economic development, op. cit., p. 9 . 
[32] Smith, Adam. An inquiry into the nature and causes of the wealth of nations. Londres: Strathan and Cadell, 1776 , p. 17 .

[33] Hirschman, $A$ bias for hope..., op. cit.p. 37 .

[34] Ellerman, op.cit. artifício é o conceito de "seqüências invertidas", que pode ser mais bem explicado por referência à teoria da dissonância cognitiva, que sustenta que mudanças em crenças ou atitudes são engendradas por certas ações, e não um prerrequisito para estas. Um exemplo, segundo Hirschman, é a Ética protestante de Weber, que se poderia argumentar ser o resultado do empreendedorismo, e não sua causa. Outro exemplo seria o surgimento da democracia. Alguns países só desenvolveram atitudes democráticas depois que as estruturas institucionais democráticas já estavam instaladas. As atitudes em si não eram conducentes ao estabelecimento das estruturas, como se poderia esperar. O possibilismo opõe-se à natureza unidirecional das seqüências de muitas abordagens teóricas. Uma tarefa importante do possibilista é, portanto, mostrar como romper essas seqüências. Outro artifício possível é procurar "conseqüências não pretendidas", ou "mudança por via de efeitos colaterais não pretendidos". O dito de Adam Smith de que "não é da benevolência do açougueiro, do cervejeiro, ou do padeiro, que esperamos nosso jantar, mas da consideração por eles de seu auto-interesse"32 é um exemplo disso: o auto-interesse é do interesse público e propicia o bem-estar geral. Outro exemplo seria a descoberta da América, que ocorreu enquanto se buscava melhorar o transporte mercantil para a Índia. O possibilista deve usar todos esses artifícios para "aguçar a percepção das avenidas disponíveis na direção da mudança"33, para entender o que possivelmente aconteceria e para deslocar a atenção dos decisores nessa direção.

Para concluir, o possibilismo é não-paternalista. Ele não deriva de abordagens tamanho-único universais e combate ativamente as armadilhas da adesão estrita a paradigmas e padrões de desempenho que põem em risco as possibilidades de identificar o queé possível nas circunstâncias locais. Nisso, ele objetiva, de fato e de forma muito persuasiva, "ajudar as pessoas a se ajudarem", como diz um dos principais mantras retóricos da política de desenvolvimento, na medida em que permite que os decisores locais aprendam de sua própria experiência, aguça a visão deles quanto ao que pode ser feito em termos de mudança social e para agir coerentemente com isso. O desenvolvimento, do ponto de vista do possibilismo, é a busca de processos endógenos, não de impulsos externos. Como argumentou Ellerman ${ }^{34}$, essa é uma qualidade rara mesmo nas abordagens do desenvolvimento dos dias de hoje.

\section{A MÃo OCULTA E A CRIAÇÃo dE TRAÇOS}

Depois de um trabalho como consultor do Banco Mundial, Hirschman publicou Developmentprojectsobserved (1967), no qual resumeas experiências que adquiriu durante visitas a vários projetos diferentes 
ao redor do globo. Quarenta anos depois, esse livro continua a ser uma análise extremamente legível e impressionante da ajuda para o desenvolvimento. Muitas de suas explanações e análises são válidas ainda hoje, entre elas o "princípio da mão oculta". Seguindo a idéia de Adam Smith da "mão invisível", a mão oculta impede que os praticantes do desenvolvimento antecipem todas as dificuldades que podem surgir no curso de um projeto: a despeito da intenção natural deles de levar em conta todos os riscos e dificuldades possíveis, sempre ocorrem contingências não previstas e inesperadas. Segundo Hirschman, isso se dá porque elas foram obscurecidas pela mão oculta. Paradoxalmente, a mera existência da mão oculta é a razão pela qual são executados projetos de desenvolvimento. Se todas as dificuldades e riscos fossem conhecidos de antemão, é provável que nem um único projeto fosse executado. Com esse argumento, Hirschman apontou um dedo irônico para a análise de custo-benefício, que se tornara o método dominante no planejamento de projetos e que se baseia no pressuposto de que todos os possíveis efeitos negativos de um projeto podem ser identificados ex-ante, permitindo assim uma decisão racional sobre proceder ou não à sua implementação.

Hirschman sustenta que um projeto de desenvolvimento só pode ser bem-sucedido a longo prazo se forem tomadas medidas adequadas em resposta a dificuldades e problemas inesperados que a mão oculta obscurece. Como em seus outros textos, ele propugna a maior flexibilidade possível e uma disposição de procurar soluções de maneiras não convencionais. Descreve o caso de uma fábrica de papel no Paquistão cujo único insumo natural era o bambu. A mão oculta impedira que os planejadores considerassem o que aconteceria se o suprimento aparentemente abundante de bambu cessasse. Isso ocorreu quando, inesperadamente, o bambu começou a florescer alguns anos depois do início das operações (o que é considerado um evento muito raro e incomum em botânica e poderia não acontecer durante um século) e depois morreu, deixando a região inteira sem os recursos necessários para a fábrica. Por sorte, os engenheiros da fábrica conseguiram identificar uma planta local cujas propriedades até então desconhecidas não só permitiam a substituição do bambu, mas também melhoravam significativamente a qualidade do papel. É claro que nem todos os casos têm um final feliz como esse: como Hirschman reconhece, problemas que surgem repentinamente podem ser tão sérios que um projeto não possa ser salvo.

Hirschman também faz uma distinção entre projetos de desenvolvimento que utilizam costumes e conhecimento locais (chamados de "aproveitamento de traços") e projetos que requerem capacidades e habilidades completamente novas, para as quais as pessoas têm de ser primeiro treinadas ("criação de traços"). Ele não 
sugere que, para funcionar, os projetos têm de ser "aproveitadores de traços", mas adverte que se não forem, terão de ser despendidos cuidados e recursos extras para adaptar o projeto ao cenário local. Sem essas adaptações, o projeto provavelmente será malsucedido. Numa época em que o mundo do desenvolvimento internacional ainda se caracterizava por uma abordagem tamanho-único, as idéias de Hirschman chegavam perto da heresia.

Em um dos ensaios do livro, ele analisou as razões para o declínio da ferrovia estatal nigeriana. As observações e as conclusões a que ele chegou mais tarde levaram à evolução de sua obra mais conhecida, Exit, voice, and loyalty (1970), na qual objetivava investigar diferentes possíveis "respostas ao declínio" na qualidade, fosse a qualidade de um produto, um serviço, um governo ou qualquer outra instituição. Na teoria econômica, o principal canal para demonstrar decepção devido a um declínio na qualidade é a "saída", o que significa simplesmente mudar de um fornecedor para outro no mercado. Todavia, a ciência política enfatiza a articulação da decepção primariamente por meio do protesto verbal ou em outras formas, ou seja, "voz". Ao teorizar sobre esses dois mecanismos e suas combinações possíveis, Hirschman estabeleceu um kit de ferramentas analíticas que poderia ser usado para identificar as "respostas ao declínio" em várias situações socioeconômicas.

\section{SAÍDA E VOZ: AUTO-SUBVERSÃO PARTE 3}

A teoria da saída e da voz, no entanto, vai muito além de meramente identificar saída evoz como respostas alternativas ao declínio. Acima de tudo, Hirschman tentou mostrar quais dessas "respostas", ou qual mistura das duas, provê a uma instituição ou organização responsável por um declínio na qualidade o mecanismo de retroalimentação necessário para que ela melhore a situação que causou a perda de qualidade.

Mais uma vez, portanto, Hirschman estava preocupado com a busca de mecanismos inerentes que levam à melhora. Mais uma vez, ele focalizava a identificação de modificadores ou remédios embutidos ou forças endógenas de recuperação que normalmente passam despercebidos, especialmente na teoria econômica convencional. No modelo de concorrência perfeita, por exemplo, produtores que não satisfazem as necessidades de seus clientes ou cuja qualidade de produto declina são simplesmente chutados para fora do mercado por via da saída automática ou da demanda de mercado. Todavia, isso não explica como esses produtores podem obter a retroalimentação necessária ou como eles são capacitados a introduzir mudanças e melhorias, uma grave omissão quando contrastada com o funcionamento dos mercados reais. Hirsch- 
man, em contrapartida, identificou a frouxidão, a variação no desempenho e o declínio na qualidade como elementos que são quase inevitáveis na produção de bens ou serviços. Mais importante, ele teorizou sobre o intervalo entre o surgimento inicial de um declínio na qualidade e o momento em que os padrões de qualidade são retomados, ou o produtor, organização ou instituição em questão é dissolvido devido ao exercício da opção "saída" ou da violência da "voz". Forjar uma moldura de tempo específica como uma janela de oportunidade limitada, identificar as ações que podem ocorrer dentro desse intervalo, bem como descrever resultados possíveis dessas ações são alguns dos vários leitmotiven da obra de Hirschman. Eles podem ser encontrados no cerne de seu efeito túnel, e também na assimetria de muitas das tentativas de identificar forças endógenas de recuperação ou modificadores embutidos.

No caso das ferrovias estatais nigerianas, clientes que estavam insatisfeitos com a qualidade do serviço mudavam com relativa facilidade e sem nenhum custo adicional substancial para o substituto perfeito, o transporte rodoviário. Hirschman concluiu que se a saída é livre e a mudança para um substituto é possível, o mecanismo de voz não é ativado. A saída livre é menos problemática do que fazer o esforço extra de vocalizar o descontentamento. Portanto, a saída livre dificulta a voz. Conseqüentemente, a autoridade ferroviária nigeriana não recebia informações sobre o motivo de seus clientes desertarem, nem sobre como melhorar seu serviço para atender às demandas dos consumidores. Isso, junto com o fato de que a ferrovia estava operando com pouca restrição orçamentária - o dinheiro do governo ingressava automaticamente - significava que a autoridade ferroviária nem sequer via a necessidade de mudar.

Todavia, a queda do Muro de Berlim destroçou a tese principal de Hirschman, de que a saída livre dificulta a voz. No começo da década de 1990, ele voltou à sua Berlim natal para examinar os eventos de $1989 \mathrm{e}$ descobriu que o destino da República Democrática Alemã, sua rápida desintegração e o inesperado desmoronamento do muro podiam ser explicados de forma muito plausível usando as ferramentas da saída e da voz ${ }^{35}$. Durante décadas, a liberdade dos cidadãos da Alemanha Oriental tinha sido severamente restringida. Qualquer pessoa que tentasse cruzar a fronteira fortificada com o Ocidente corria o risco de receber um tiro ou ser seriamente punida. Mas no verão de 1989 a Hungria e a Tchecoslováquia inesperadamente abriram suas fronteiras até então impenetráveis para a Alemanha Ocidental e a Áustria. Em conseqüência, os alemães orientais, que podiam viajar facilmente para esses dois "Estados socialistas irmãos", de repente tinham uma oportunidade quase isenta de riscos de deixar o país e emigrar para o Ocidente. No decorrer do verão, centenas de milhares foram para a Alemanha Ocidental.

[35] Hirschman, A propensity to selfsubversion, op, cit. 
[36] Idem, Crossing boundaries: selected writings, op. cit., p. 86.
Ao mesmo tempo, pela primeira vez desde o levante de 1953, as massas começaram a tomar as ruas da República Democrática Alemã e exigir reformas políticas, inspiradas pela glasnost e pela perestroika na União Soviética. A cidade de Leipzig logo se tornou o centro dos protestos, com manifestações de massa todas as segundas-feiras depois de uma missa tradicionalmente dedicada à paz mundial, que servia havia muito tempo como ponto de encontro para a oposição política clandestina. Quando o número de participantes cresceu exponencialmente do final do verão ao começo do outono, essas manifestações se tornaram uma séria ameaça à estabilidade interna do sistema político. $O$ interessante é que os manifestantes pediam não só reformas e democratização. Seu slogan principal, que se tornou uma espécie de grito de guerra nos primeiros meses dos protestos crescentes e que era uma reação clara ao êxodo palpável que privava o país de trabalhadores treinados e especializados, era "Wir bleiben hier!" - "Nós vamos ficar aqui!".

Hirschman argumentou que nesse caso o potencial para saída (a possibilidade de sair através dos países vizinhos) capacitava a voz e dava aos que protestavam a coragem de se fazerem ouvidos. Adisponibilidade de uma opção de saída relativamente fácil era a precondição necessária para a voz, não um obstáculo a ela, como Hirschman afirmava antes. O slogan "Wir bleiben hier!" podia ser interpretado como "mudançajá, senão nós também partiremos". A saída era usada como ameaça e como um tipo de chantagem política; dava à voz mais peso - se bem que não o suficiente. Todavia, ela não levou a melhoras dentro da RDA nem à sua sobrevivência. Ao contrário, o governo da Alemanha Oriental era tão relutante a ceder que o protesto se tornou ainda maior e levou ao completo colapso político do país. Que a saída pode reforçar a voz foi a lição aprendida da queda da Cortina de Ferro; mas ela podia às vezes ser tardia demais para melhorar significativamente a situação. Com essa conclusão, a autosubversão de Hirschman atingiu seu clímax.

A análise da saída e da voz sempre foi cara a Hirschman. Isso se mostra nos muitos ensaios dedicados ao tema; ele também escreveu que ao longo de sua vida teve repetidamente de tomar decisões entre saída e voz num nível muito pessoa $3{ }^{36}$. Em sua carreira científica, a publicação de Exit, voice, and loyalty foi uma espécie ponto de virada. A partir daquele momento, Hirschman concentrou-se ainda mais na análise histórica, ou em teorias que explicam um certo comportamento humano.

\section{A OUTRA Lógica da AÇÃo COLETIVA}

Outro dos temas de Hirschman foi explicar por que os indivíduos se envolvem na ação coletiva. Desde meados da década de 1960 , a imagem do caronista que Mancur Olson pintou de forma tão vívida em seu Logic of collective action (1965) passou a dominar as ciências sociais. 
Olson argumentava que como o caronista pode colher os benefícios da ação coletiva sem se engajar nela, não tem nenhum incentivo racional para participar - uma atitude que inibe seriamente a possibilidade de ação coletiva em grande escala. Hirschman, cuja vida foi caracterizada por um engajamento constante na ação coletiva, não concordava com esse modelo simplista de comportamento e procurava outras explicações para o fato claramente observável de que os indivíduos na verdade se engajam na ação coletiva. Ironicamente, o estudo de Olson exerceu sua influência mais forte no mundo acadêmico em uma época em que estudantes norte-americanos e europeus tomavam as ruas en masse para exigir mudanças sociais e políticas; ligar a TV no noticiário era quase suficiente para provar que Olson estava errado.

EmShiftinginvolvements (1982), Hirschman analisa padrões cíclicos de engajamento em ação coletiva. Enquanto os anos de 1960 foram uma época de forte ação coletiva, as décadas de 1950 e 1970 caracterizaram-se por uma concentração na arena privada, e não na pública. Hirschman explica isso assumindo que a análise de custo-benefício individual funciona diferentemente do que era suposto na teoria convencional. Para ele, o "benefício" é derivado não só do resultado de um engajamento, mas também do próprio ato de engajar-se. $\mathrm{O}$ engajamento não é, portanto, só um custo, como sugere a teoria econômica. Essa suposição simples pode explicar muito mais realisticamente por que os indivíduos se engajam em ações coletivas. Não obstante, a disposição de se engajar em ações coletivas tem seus limites: se a ação pública não produz as mudanças desejadas, a prontidão para se engajar diminui e, passado algum tempo, há um completo retorno à esfera privada. É clara a influência de Colorni e seu grupo na formulação desse raciocínio. E mais uma vez Hirschman está preocupado com as ações executadas em um intervalo específico de tempo e seus resultados.

Esse tópico foi retomado na coletânea de ensaios Getting ahead collectively (1984), na qual Hirschman analisou movimentos de base na América Latina e teorizou sobre como era possível explicar o sucesso ou fracasso da ação coletiva e cooperativa. Ele formulou o "Princípio de conservação e mutação da energia social", sugerindo que a disposição de um indivíduo para se engajar em ações coletivas pode permanecer adormecida por longos períodos mas, de repente, ser reativada. Mesmo queengajamentos anteriores tenham sido malsucedidos, as lembranças positivas de extrair satisfação da ação podem levar o indivíduo a se engajar repetidas vezes - uma idéia que antecipa a teoria do capital social.

\section{O CÉTICO OTIMISTA: O POSSIBILISMO REVISITADO}

Argumentei queo possibilismo não apenas descreve a abordagem de Hirschman do desenvolvimento na América Latina, mas pode 
também ser usado para definir seu método analítico geral. Nesta parte final, resumirei os elementos e as ferramentas que, em minha opinião, constituem o possibilismo e, portanto, ampliam o escopo original da abordagem tal como Hirschman a utilizou. Ao mesmo tempo, recapitularei aquelas influências biográficas que ajudaram no surgimento do possibilismo. Os principais "ingredientes" $e$ características do possibilismo devem então ficar suficientemente claros para ser utilizáveis por cientistas sociais e por praticantes do desenvolvimento interessados.

Os nazistas forçaram Hirschman a cruzar fronteiras, a fazer travessias não autorizadas, ou invasões. Ele viveu em diferentes países europeus antes de emigrar para os Estados Unidos. Ironicamente, durante seu trabalho para Varian Fry, ele de forma deliberada usou o método de travessia não autorizada como um meio de salvar vidas de muitos perseguidos pelos alemães. Mas não foi só a invasão física que fez parte de sua vida. No trabalho acadêmico, Hirschman também é um invasor, um acadêmico que sempre gostou de cruzar fronteiras ideológicas em sua própria disciplina e nas outras ciências sociais. Isso também explica por que ele escolheu Crossing boundaries (1998) como título de uma coletânea de ensaios. Ser um economista sem tocar em outras disciplinas como sociologia, história, filosofia, psicologia, ciência política e literatura é impensável para Hirschman. Ele próprio cunhou a expressão trepassing, a travessia não autorizada, ou invasão, para seu modus operandi. Todavia, essa invasão só é possível quando seé curioso e sensível a outras perspectivas, opiniões e pontos de vista e se tem um conhecimento profundo de outras disciplinas. Hirschman podia ser um economista por formação, mas a impressionante extensão de sua invasão dá a ele a aparência de um dos últimos Universalgelehrten (sábio universal ou polímata), ao estilo do século XVIII.

Outro aspecto da invasão de Hirschman talvez seja ainda mais importante na compreensão de sua abordagem possibilista. Hirschman foi obrigado a cruzar não apenas fronteiras políticas, mas também lingüísticas e culturais. Ele fala fluentemente alemão, francês, italiano, inglês e espanhol e teve de se adaptar a diferentes culturas; isso o ensinou que tentativas de "traduzir" não só palavras mas também conceitos e idéias para outras línguas e contextos culturais leva com freqüência a mal-entendidos. Ainda muito jovem e como resultado da invasão, Hirschman deixou de ser um "falante nativo" de uma única língua ou mentalidade dominante. Ao ser exposto a diferentes línguas e culturas, ele adquiriu um alto grau de sensibilidade ao contexto e à futilidade de tentar impor idéias exógenas em cenários endógenos. Por conseqüência, em vez de aderir a abordagens modelares gerais, que são impostas por forasteiros, o possibilismo procura o que pode ser feito com os recursos disponíveis localmente "que estão ocultos, 
dispersos ou mal utilizados" 37 . Trata-se de um esforço consciente de sensibilidade ao contexto, cuja falta está no cerne de muitos empreendimentos desenvolvimentistas malsucedidos.

Os textos de Hirschman muitas vezes originam-se de uma reação crítica a teorias ou ideologias dominantes, cujas fragilidades são destacadas pelas novas percepções dele, as quais, por sua vez, costumam levar à formulação de teorias completamente novas $3^{3}$. Em economia, onde escolas de pensamento divergentes tendem a se entrincheirar em posições antagônicas, Hirschman evitou as armadilhas de abraçar muito estritamente qualquer teoria. $\mathrm{O}$ mote de sua obra, como ele disse 39 , poderia ser descrito pelo slogan "Não é necessariamente assim" - a máxima de Sportin' Jack, da ópera Porgy and bess, de Gershwin. Essa é uma atitude cética em relação a todas as formas de constructos teóricos, inclusive o dele próprio - manifestada por sua propensão recorrente à auto-subversão. Acima de tudo, sua abordagem é uma expressão de uma busca genuína pelo conhecimento. Em vez de fazer os fenômenos observados se encaixarem em uma moldura teórica inflexível, Hirschman adapta sua teoria e a de outros para explicar a realidade observável que o cerca.

Contudo, subjacente à sua atitude de ceticismo, há a certeza (ou pelo menos a esperança) de que em cada situação existe a possibilidade inerente de identificar uma solução para um problema específico. Isso se baseia em suas experiências enquanto se opunha ativamente ao fascismo na Itália e na França. Hirschman é um cético otimista, que acredita firmemente que situações aparentemente desesperadoras sempre ocultam algum tipo de modificador ou remédio embutido, algumas forças endógenas de recuperação, artifícios de regulação do ritmo ou mecanismos de indução por meio dos quais uma situação subótima pode ser superada ou pelo menos melhorada a partir de dentro. A busca por esses aspectos é característica principal do possibilismo ${ }^{40}$. Sua concentração em soluções endógenas é o completo oposto da "superconfiança na solvibilidade de todos os problemas" por meio de expertise externa ${ }^{41}$ que caracteriza muitas abordagens desenvolvimentistas.

Visto de um ângulo diferente, o possibilismo é orientado para soluções, tentando encontrar possíveis avenidas de escape endógenas, seja nos Pireneus, seja nas ciências sociais.

São, portanto, precondições necessárias para a identificação dessas avenidas, e de fato para o próprio possibilismo, a análise em profundidade das circunstâncias locais e a capacidade de observar fenômenos de diferentes perspectivas por meio da busca de racionalidades ocultas, seqüências invertidas, conseqüências não pretendidas e males que vêm para bem. Nessa busca, uma Weltanschaunng fixa seria apenas um obstáculo - especialmente porque, segundo Hirschman,
[37] Idem, The strategy of economic development, op. cit., p. 5 .

[38] "Eu gosto de sublinhar as exceções a uma teoria, mas ocasionalmente gosto de construir minha própria teoria" (ibidem, p. 95).

[39] Idem, $A$ propensity to self-subversion, op. cit., pp. 43 e 87

[40] O título de outra coletânea de ensaios é A bias for hope..., op. cit.

[41] Hirschman. "Prefácio".In:Ellerman, op.cit., p. xviii. 
[42] Ellerman, op. cit., p.3.

[43] Keynes, op. cit., p.383.

[44] Hirschman, The strategy of economic development, op. cit., p. 11. as soluções para um problema devem ser encontradas dentro de um intervalo específico, de uma magnitude de tempo bem definida, antes que tudo possa se perder ou uma mudança para melhor se torne impossível. A busca de Hirschman por soluções ocorre sob uma restrição temporal, sob pressão - mas sua abordagem pelo menos supõe que uma solução ou avenida de escape possa ser encontrada.

O possibilismo contém assim uma rejeição a priori de uma Überbau [superestrutura] ideológica. Esta pode ser entendida como um meio de se livrar dos ídolos baconianos que dificultam a busca da verdade e de soluções possíveis. Não é, todavia, uma rejeição dos princípios morais ou de uma base moral para a ação. Estes são claramente visíveis na vida de Hirschman e em sua longa luta contra o fascismo. Antes, trata-se de um apelo à abertura da mente, propiciando a análise de uma dada situação que parte de uma tabula rasa ideológica. Pode ser vista também como uma convocação à multidisciplinaridade e à invasão deliberada de fronteiras, e sublinha mais uma vez que o possibilismo resulta da invasão de fronteiras levada a cabo pelo próprio Hirschman, de sua rejeição de uma Weltanschauung e de sua propensão à auto-subversão.

Qual é a relevância prática e contemporânea dessa metodologia? Como mostraram a recente controvérsia sobre diferentes abordagens do desenvolvimento e a crítica pós-moderna, ainda é comum a adoção de teorias que abrangem tudo e a proposição de soluções unificadas. Mais preocupante ainda, desde os primeiros dias da "ajuda" na década de1950, as agências de desenvolvimento perceberamodesenvolvimento como um processo que pode "ser manejado do modo como a varíola foi vencida ou alguém foi posto na Lua" 42 . Parece ser uma tendência humana imaginar melhores práticas e teorias grandiosas e acreditar que é possível delas derivar ações coerentes. É claro que é difícil se soltar das amarras de seja qual for a Weltanschauung e a ideologia às quais se adere, como notou Keynes em seu famoso trecho da Teoriageral, quando escreveu que "homens práticos, que acreditam estar bastante isentos de qualquer influência intelectual, são normalmente escravos de algum economista morto"43. Mas por que não, pelo menos, tentar? O possibilismo nos mostra como. A descrição de Hirschman da "síndrome do economista visitante", na qual peritos externos emitem prescrições de política invocando "princípios e remédios universalmente válidos" depois de "uma familiarização estritamente mínima com o paciente" 44 ainda descreve corretamente o funcionamento de muitas agências doadoras. Uma das razões para as falhas da ajuda ao desenvolvimento talvez seja o fato de que as agências de auxílio costumam tratar seus pacientes rápido demais com a mesma medicação. $O$ possibilismo, ao contrário, propugna a análise em profundidade do paciente antes de concluir quais passos médicos são possíveis em cada caso. 
Embora autores como Easterly saúdem abordagens passo a passo e autores pós-modernistas defendam um fim das narrativas grandiosas, os meios de alcançar isso normalmente permanecem pouco claros.É nesse sentido que o possibilismo se torna útil. Ele fornece uma estrutura pragmática, orientada para soluções para pensar "fora dos padrões" e para descobrir o que é possível em quaisquer circunstâncias dadas. Isso, é claro, não garante interpretações ou soluções engenhosas. Mas os elementos do possibilismo fornecem as ferramentas e as precondições necessárias para uma análise que pelo menos tente minimizar o tipo de influências ideológicas, abordagens e interpretações externas uniformes que tão raramente foram úteis. Em conformidade com as obras de Hirschman, a metodologia pode ser aplicada no nível do macro e do microprojeto, e é portanto útil para o gerente de projeto e para o trabalhador de base pelo desenvolvimento, bem como para o planejador de estratégias de desenvolvimento nacional. O possibilismo é útil também fora do contexto do desenvolvimento. As interpretações possibilistas feitas por Hirschman da ação coletiva, da tolerância da desigualdade, e da saída e da voz mostraram que essa abordagem é aplicável também a uma ampla gama de fenômenos sociais, econômicos e políticos.

Isso tudo não se resume em bom senso? Talvez. Mas dado o discutível histórico de desempenho das políticas de desenvolvimento ao longo de mais de cinqüenta anos, a dominância de modelos como o Consenso de Washington, a popularidade de ideais utópicos como a noção de acabar com a pobreza mundial, ou a idéia de que dobrar a ajuda monetária vai finalmente produzir os resultados desejados, parece haver um grau assombrosamente pequeno de bom senso na teoria e na prática do desenvolvimento contemporâneas. Aparentemente, é preciso uma vida admirável e complexa para que surja uma idéia de bom senso como o possibilismo. Mas no caso de esta discussão da aplicabilidade obscurecer um ponto importante, não se deve esquecer que nos frenesis do começo do século XX, o possibilismo salvou repetidas vezes a vida de Hirschman.

PHILIPP H. LePENIES éeconomista sênior no departamento de estratégia do KFW Entwicklungsbank (philipp.lepenies@kfw.de). Seus interesses de pesquisa incluem a história do desenvolvimento. As opiniões expressas neste artigo são de exclusiva responsabilidade dele e não refletem as visões do KFW Entwicklungsbank.

Recebido para publicação

em 21 de outubro de 2008.

NOVOS ESTUDOS

CEBRAP

83, março 2009

pp. $65-88$ 